\title{
ANTIDIABETIC AND ANTIHYPERLIPIDAEMIC ACTIVITY OF NELUMBO NUCIFERA GAERTN ETHANOL SEED EXTRACT IN STREPTOZOTOCIN INDUCED DIABETIC RATS
}

\author{
ALOK BHARDWAJ ${ }^{1 *}$, KETAN. P. MODI ${ }^{2}$ \\ ${ }^{1}$ School of Pharmacy, RK University, Rajkot, Gujarat, India, Assistant Professor, Lloyd Institute of Management \& Technology, \\ Greater Noida, ${ }^{2}$ B. K. Mody Govt. Pharmacy College, Rajkot, Gujarat, India \\ Email: alok.nicholas@gmail.com
}

Received: 19 Jul 2017 Revised and Accepted: 31 Aug 2017

\section{ABSTRACT}

Objective: The main objective of the study was to investigate the effect of ethanol seed extracts of Nelumbo nucifera Gaertn (Nymphaeaceae) as antihyperglycemic, anti-hyperlipidemic and antioxidant activity in streptozotocin-induced diabetic rats.

Methods: Diabetes was induced in wistar albino rats by administration of streptozotocin (single intraperitoneal dose of $60 \mathrm{mg} / \mathrm{kg} \mathrm{B}$. W). The ethanol extract of $N$. nucifera seed at a dose of 200 and $400 \mathrm{mg} / \mathrm{kg}$ body weight was administrated at a single dose per day to STZ induced diabetic rats for a period of $42 \mathrm{~d}$. The different pharmacological parameters were evaluated. The effect of ethanol seed extract of $N$. nucifera on insulin, blood glucose, urea, creatinine, $\mathrm{HbA}_{1} \mathrm{C}$, serum protein, albumin, globulin, serum enzymes, serum lipid profiles, lipid peroxides (LPO) and other antioxidant enzymes like catalase (CAT), glutathione peroxidase (GPx), superoxide dismutase (SOD) and reduced glutathione (GSH) were measured in the diabetic rats.

Results: In the acute toxicity study ethanol seed extract of Nelumbo nucifera were non-toxic at $2000 \mathrm{mg} / \mathrm{kg}$ in rats. The ethanol extract of Nelumbo nucifera seed showed significant reduction in blood glucose $(p<0.05)$, serum enzymes (SGPT, SGOT, ALP) ( $p<0.05$ ), lipid parameters (TC, TG, VLDL, LDL) $(p<0.05)$ except HDL and significantly increased insulin $(p<0.05)$, HDL $(p<0.05)$, GPx, GSH, SOD and CAT $(p<0.05)$ at the dose of $400 \mathrm{mg} / \mathrm{kg}$ when compared with the diabetic-induced control.

Conclusion: The present study suggested that the NNSE has significant $(p<0.05)$ antihyperglycemic, antihyperlipidemic and antioxidant activity in STZ induced diabetic rats. These results clearly indicate that Nelumbo nucifera is effective against free radical-mediated diseases, thus replacing the synthetic ones.

Keywords: Nelumbo nucifera, Antidiabetic activity, Streptozotocin, Serum lipid profile, Antioxidant enzymes

(C) 2017 The Authors. Published by Innovare Academic Sciences Pvt Ltd. This is an open access article under the CC BY license (http://creativecommons.org/licenses/by/4.0/) DOI: http://dx.doi.org/10.22159/ijpps.2017v9i10.21455

\section{INTRODUCTION}

Diabetes mellitus is a metabolic disorder resulting from a defect in insulin secretion, insulin resistance or both. Insulin deficiency, in turn, leads, to chronic hyperglycemia with disturbances of carbohydrates, fat and protein metabolism [1]. Globally, the estimated case of diabetes and projection for the year 2030, as given by the International Diabetes Federation is 350 million [2]. Currently available treatment of diabetes mellitus includes oral hypoglycemic agents and insulin. However, these current drugs do not restore normal glucose homeostasis and they are not free from side effects [3]. In view of the adverse effects associated with the synthetic drugs and as plants are safer, cheaper and much effective, conventional antidiabetic plants can be explored [4]. Over 400 traditional plants have been reported for the treatments of diabetes [5]. Furthermore, after the World Health Organization recommended, investigation of hypoglycemic agents from medicinal plants has become more important [6]. Recently, some medicinal plants have been reported to be useful in the treatment of diabetes and have been used empirically as antidiabetic and antihyperlipidemic agents worldwide. Antihyperglycemic activity of the plants is mainly due to their ability to restore the function of the pancreas by causing an increase in insulin output or inhibiting the absorption of glucose or to the facilitation of metabolites in insulindependent processes.

The plant Nelumbo nucifera Gaertn (Nymphaeaceae) is the currently recognized name for this species, which has been classified previously as Nelumbium speciosum (Wild) and Nymphaea nelumbo. Nelumbo nucifera Gaertn (Nymphaeaceae) is widely distributed plant in Southeast Asia. It has many synonyms like Indian lotus, sacred lotus etc. Lotus is considered sacred in many religions as a symbol of purity, divine beauty and enlightenment. It is one of the most important medicinal plants in India. Indian population mainly depends on the traditional system of medicine to maintain their physical and psychological health. Herbal medicines have given encouraging results and can be used as an important adjuvant therapy [7].

It has been concluded from various studies that there is no experimental evidence of antidiabetic effect of the plant. Therefore the present work was undertaken to explore the antidiabetic and hypolipidemic potentials of $N$. nucifera ethanol seed extract (NNSE) of the plant in streptozotocin (STZ) induced diabetic rat.

\section{MATERIALS AND METHODS}

\section{Plant material}

Seeds of the plant were purchased from the bank of Yamuna and Hinden river and Khari Baoli market, Chandni Chowk, Delhi. The plant was identified and authenticated by the Dr Anjula Pandey principal scientist, NBPGR, Pusa Institute, New Delhi (identification voucher no.: NHCP/NBPGR/2014-10). The plant seeds were dried in air for complete drying.

\section{Chemicals and reagents}

Insulin was purchased from Jain Diagnostic Pvt. Ltd., New Delhi. STZ was purchased from Sigma-Aldrich, India. Isotonic saline, sodium carbonate, paraformaldehyde, glibenclamide and amyloglucosidase were purchased from Central Drug House (Pvt) Laboratory (CDH) Dariyaganj New Delhi. ELISA kit, Glucose assay kit, cholesterol (TG) reagent, triglyceride (TC) reagent, LDL-HDL cholesterol kit, serum aspartate aminotransferase (AST) and alanine aminotransferase (ALT) were measured using commercially available kits from Recombinogen Pvt. Ltd, New Delhi, India and Erba Diagnostics, Mumbai, India. All others unlabelled and reagents were analytical grade.

\section{Extract preparation}

The seeds were dried and seed powder was made by a domestic grinder. The powdered drug of the plant has been subjected to 
solvent extraction, with petroleum ether, chloroform, ethanol and water. After complete extraction, the solvent was evaporated at room temperature under pressure. The percentage yield, colour another characteristic of the semisolid was determined. The extract was preserved in a desiccator at $4{ }^{\circ} \mathrm{C}$ till further use.

\section{Animal care and selection}

Adult male albino rats (150-200 g), raised in the animal house of R. I. T Greater Noida have been used in the study. They were housed in polypropylene cages individual rat per cage and kept in a room maintained at $25 \pm 2{ }^{\circ} \mathrm{C}$ with a 12 -h light/dark cycle. They were allowed to acclimatize for $7 \mathrm{~d}$ before the experiments and were given free access to standard laboratory feed and water ad libitum. Animals described as fast were deprived of food for $16 \mathrm{~h}$ but had free access to water. The protocol was approved by the Institutional Animal Ethics Committee (IAEC). (Approval no RIT/IAEC/2016/JAN/06)

\section{Acute toxicity study}

The acute toxicity study was performed according to OECD guideline $2000-5000 \mathrm{mg} / \mathrm{kg}$ BW. The wistar albino rat of either sex weighing 150-200 g (total animals=15) was randomly divided into five different groups $(n=3)$. After an overnight fasting ethanol extract of the plant (seed) were administered orally in various doses $(250$, $500,1000,2000 \mathrm{mg} / \mathrm{kg}$ ) suspended in $0.5 \%$ CMC (carboxymethyl cellulose). The first group was maintained as a control and administered the vehicle only. The animals were observed for behavioural changes, locomotor dysfunction and finally for any mortality for $72 \mathrm{~h}$. Toxic symptoms were also observed.

\section{Induction of diabetes}

Diabetes in the rats was rendered by a single intraperitoneal dose of $60 \mathrm{mg} / \mathrm{kg}$ B.W. Streptozotocin (STZ) dissolved in ice-cold $0.1 \mathrm{M}$ citrate buffer ( $\mathrm{pH} 4.5)$. After $72 \mathrm{~h}$, fasting blood glucose (FBG) levels were measured and only those animals which showed blood glucose levels $>250 \mathrm{mg} / \mathrm{dl}$ were separated and used for the study. The diabetic animals were stabilized for five days and the day on which hyperglycemia confirmed were designated as day $0[8,9]$.

\section{Experimental design}

The STZ induced diabetic rats were divided into five groups of six each. The group I received normal saline and served as normal control. Group II received $0.2 \% \mathrm{CMC}$ and served as diabetic control, Group III and IV received an ethanol seed extract of N. nucifera at a dose 200 and $400 \mathrm{mg} / \mathrm{kg} / \mathrm{p}$. o respectively. Group $\mathrm{V}$ received the standard drug glibenclamide $10 \mathrm{mg} / \mathrm{kg}$. The treatment was continued for $42 \mathrm{~d}$. Fasting blood samples were collected at week 1, 2, 3, 4, 5, 6, 7 of drug administration. Food and water were monitored regularly daily for each rat during $42 \mathrm{~d}$ of the experimental period.

\section{Glucose tolerance test in normal Wistar albino rats}

After three weeks of the treatment, the oral glucose tolerance test (OGTT) was performed on overnight fasted normal, diabetic and extract treated rats. Glucose ( $2 \mathrm{~g} / \mathrm{kg}$ body weight) was given orally and blood glucose level was measured at $0,30,60$, and 120 min after administration of glucose [10].

\section{Biochemical studies}

Each animal from the different groups was weighed than blood samples were collected from the retro-orbital plexus method in test tubes, left for 8-10 min to clot and then centrifuged at $3000 \mathrm{r}$. p. $\mathrm{m}$ to separate the serum. The centrifuged serum was subjected to biochemical parameters. The albino rats of all groups were fasted and sacrificed by euthanasia using halothane at the end of $42 \mathrm{~d}$ treatment. Liver and kidney are isolated from one animal of each group and a small portion was used for histopathology and other half portion was used for biochemical parameters by making homogenate using a centrifuge.

The plasma insulin was assayed by ELISA method using the ELISAkit [11]. Blood glucose by glucose assay kit [12]. Glycosylated hemoglobin (HbA1C) estimation was carried out by a new colourimetric method [13]. Urea estimation was carried out by the method [14] of Varley; serum creatinine was estimated by the method of Owen et al. [15]. Serum protein was determined by the quantitative calorimetrically method by using with the Folin's phenol reagent [16]. The total protein minus the albumin gives the value of globulin, aspartate aminotransferase (AST) and alanine aminotransferase (ALT) was measured spectrophotometrically by utilizing the method of [17], serum alkaline phosphatase (ALP) was measured by the method of [18]. Serum total cholesterol (TC) [19], total triglycerides (TG) [20], high-density lipoprotein cholesterol (HDL-C) [21], low-density lipoprotein cholesterol (LDL-C) [22], were analyzed. Liver glycogen content was measured according to the method of Murat and Serfaty [23], catalase (CAT) [24], glutathione peroxidase (GPx) [25], superoxide dismutase (SOD) [26], lipid peroxidation (LPO) [27], and reduced glutathione (GSH) [28], in serum, liver and kidney were measured in the normal, STZ induced diabetic and drug-treated rats.

\section{Histopathological study}

\section{Biochemical estimation}

Animals were sacrificed by euthanasia using halothane. Liver and kidney were isolated, the half portion was used for histopathological examination and half portion was used for determination of biochemical and antioxidant assays by making homogenate using a centrifuge. Some of the parameters were assessed by UV and some with the help of suitable kits.

\section{Statistical analysis}

Statistical analysis was carried out using GraphPad Prism 5.0 (version 5.03). All the experimental data were expressed as mean \pm SEM. Results comparisons were carried out by using a 1-way analysis of variance followed by the Tukey's multiple comparison test to compare means among the groups. For the statistical tests, A value of $(p<0.05)$ was considered to be significant.

\section{RESULTS}

\section{Phytochemical screening}

The distribution of different phytochemical constituents in ethanolic seed extract of $N$. nucifera was evaluated qualitatively. The presence of alkaloid, flavonoid, phenol, saponin, steroid, tannin, terpenoid, sugar, glycoside and xanthoprotein has been confirmed in the ethanol seed extract of $N$. nucifera.

\section{Glucose tolerance tests in normal wistar albino rats}

Effect of glucose tolerance tests in normal wistar albino rats was studied. It was observed that seed extract at the dose of $200 \mathrm{mg} / \mathrm{kg}$ and $400 \mathrm{mg} / \mathrm{kg}$ significantly $(p<0.05)$ reduced the blood glucose level as compared with normal control rat. Standard drug glibenclamide also showed significant blood glucose lowering effect in 30, 60 and $120 \mathrm{~min}$. The effects of the seed extract on glucoseloaded rats have been shown in the (table 1).

Table 1: Effect of NNSE on blood glucose levels in glucose loaded hyperglycemic rats

\begin{tabular}{|c|c|c|c|c|}
\hline \multirow[t]{2}{*}{ Groups (n=6) } & \multicolumn{4}{|c|}{ Fasting blood sugar in mg/dl } \\
\hline & $\mathbf{0}$ min & $30 \mathrm{~min}$ & $60 \mathrm{~min}$ & $120 \mathrm{~min}$ \\
\hline Control $(0.2 \% \mathrm{CMC})$ & $76.66 \pm 3.35$ & $120.84 \pm 4.75$ & $107.69 \pm 4.65$ & $93.10 \pm 3.40$ \\
\hline NNSE (200 mg/kg) & $79.75 \pm 3.77$ & $93.68 \pm 3.25^{* * * a}$ & $83.48 \pm 2.59^{* * *}$ & $75.58 \pm 3.53^{* *}$ \\
\hline NNSE (400 mg/kg) & $81.36 \pm 3.83$ & $103.43 \pm 2.45^{b}$ & $93.74 \pm 2.46^{\mathrm{b}}$ & $78.67 \pm 3.24^{b}$ \\
\hline Std (10 mg/kg) & $76.28 \pm 2.75$ & $103.05 \pm 2.57 \mathrm{~b}$ & $86.36 \pm 2.14^{\mathrm{b}}$ & $74.22 \pm 3.10^{\mathrm{b}}$ \\
\hline
\end{tabular}

Values are expressed as mean \pm SEM, $n=6$ in each group, ${ }^{* * *} p<0.05$-Comparison made between normal control, diabetic and drug treated (a=normal control vs. diabetic control, $b=$ diabetic control vs. treated) 
Assessment of hypoglycemic activity of NNSE in normal wistar albino rats

Normo-Hypoglycemic activity was carried out on the normal rats by dividing the wistar albino rats into five groups of six each. Administration of the seed extract was found to reduce blood glucose level in normoglycemic rats, both in single as well as multiple dose administration for $2 \mathrm{w}$. In a single dose study the maximum reduction in blood glucose was found to be at $60 \mathrm{~min}$ for $200 \mathrm{mg} / \mathrm{kg}, 30 \mathrm{~min}$ for $400 \mathrm{mg} / \mathrm{kg}$. In the multiple dose study, the treated rats showed a significant reduction $(p<0.05)$ in blood glucose levels on $\mathrm{d} 7,14$ and the values returned to the pretreatment levels by $21 \mathrm{~d}$.

\section{Effect of NNSE on fasting glucose level}

\section{Antihyperglycemic activity}

According to the groups, the animals were given treatment and their blood glucose level was monitored for a period of six $\mathrm{w}$. There was a significant effect of STZ on blood glucose level of diabetic rats when compared with normal control group rats. Fasting blood glucose (FBG) levels were measured and only those animals which showed blood glucose levels $>250 \mathrm{mg} / \mathrm{dl}$ were separated and used for the study. The blood glucose level was recorded regularly. The fasting blood glucose levels in STZ induced diabetic rats before treatment were $240-250 \mathrm{mg} / \mathrm{dl}$. Administration of the seed extract for $6 \mathrm{w}$ leads to a significant $(p<0.05)$ fall in blood glucose levels. At the end of experiment blood, glucose level was $(116.53 \pm 8.36)$ and $(102.88 \pm 8.42) \mathrm{mg} / \mathrm{dl}$ at the doses of 200 and $400 \mathrm{mg} / \mathrm{kg}$ of NNSE respectively (table 2).

Effect of NNSE on body weight of normal, diabetic and drugtreated rats

In this study, STZ induced diabetic rats showed significant $(p<0.05)$ reduction in body weight as compared to NNSE (200 and 400 $\mathrm{mg} / \mathrm{kg}$ ) group. Administration of standard drug glibenclamide significantly increased the body weight within $4 \mathrm{~W}$. So finally the body weight of the diabetic control group significantly $(p<0.05)$ decreased as compared with the normal control group.

Table 2: Antidiabetic effect of NNSE on blood glucose levels in STZ induced diabetic rats

\begin{tabular}{|c|c|c|c|c|c|c|}
\hline \multirow{2}{*}{$\begin{array}{l}\text { Groups } \\
(n=6)\end{array}$} & \multicolumn{6}{|c|}{ Fasting blood sugar in $\mathrm{mg} / \mathrm{dl}$} \\
\hline & Week 1 & Week 2 & Week 3 & Week 4 & Week 5 & Week 6 \\
\hline \multirow[t]{2}{*}{ I } & 77.22 & 83.82 & 84.67 & 84.20 & 83.73 & 75.85 \\
\hline & \pm 5.36 & \pm 5.23 & \pm 3.43 & \pm 3.50 & \pm 3.08 & \pm 8.18 \\
\hline \multirow[t]{2}{*}{ II } & 267.87 & 272.54 & 278.88 & 287.37 & 295.18 & 307.48 \\
\hline & $\pm 6.41^{* * *}$ & $\pm 4.88^{* * * a}$ & $\pm 5.22^{* * * a}$ & $\pm 5.25^{* * * a}$ & $\pm 4.90^{* * * a}$ & $\pm 8.45^{* * * a}$ \\
\hline \multirow[t]{2}{*}{ III } & 276.31 & 184.40 & 148.91 & 142.32 & 134.56 & 116.53 \\
\hline & $\pm 7.89 \mathrm{~b}$ & $\pm 3.16^{* * * \mathrm{~b}}$ & $\pm 6.07^{* * * \mathrm{~b}}$ & $\pm 5.91^{* * \mathrm{~b}}$ & $\pm 5.13^{* * \mathrm{~b}}$ & $\pm 8.36^{* * * \mathrm{~b}}$ \\
\hline \multirow[t]{2}{*}{ IV } & 276.58 & 206.23 & 175.48 & 149.73 & 135.59 & 102.88 \\
\hline & $\pm 7.56^{\mathrm{b}}$ & $\pm 10.74^{* * * b}$ & $\pm 10.30^{* * * \mathrm{~b}}$ & $\pm 11.16^{* * * b}$ & $\pm 7.01^{* * * \mathrm{~b}}$ & $\pm 8.42^{* * * b}$ \\
\hline \multirow[t]{2}{*}{ V } & 272.51 & 218.38 & 160.14 & 138.89 & 106.80 & 90.76 \\
\hline & $\pm 6.27^{\mathrm{b}}$ & $\pm 11.44^{* * * \mathrm{~b}}$ & $\pm 8.96^{* * * \mathrm{~b}}$ & $\pm 5.10^{* * * \mathrm{~b}}$ & $\pm 5.36^{* * * \mathrm{~b}}$ & $\pm 8.34^{* * * b}$ \\
\hline
\end{tabular}

Values are expressed as mean $\pm \mathrm{SEM}, \mathrm{n}=6$ in each group, ${ }^{* * *} p<0.05$-Comparison made between normal control, diabetic and drug treated (a=normal control vs. diabetic control, $b=$ diabetic control vs. treated)

\section{Blood glucose level and other parameters}

The effect of NNSE on the serum insulin, glucose, urea, creatinine and glycosylated haemoglobin (HbA1C) of normal and diabetic rats are shown in table 3 . The results showed that the insulin level was significantly $(p<0.05)$ reduced in diabetic rats (Group II) compared to normal rats (Group I) but the other biochemical parameters like glucose, urea, creatinine and $\mathrm{HbA} 1 \mathrm{C}$ were significantly $(p<0.05)$ increased in diabetic rats as compared to control rats. In case of NNSE treated diabetic rats (Groups III-IV) there was a significant $(p<0.05)$ increase in insulin level and a decrease in other biochemical parameters (table 3).

Table 3: Effect of NNSE on the serum insulin, glucose, urea, creatinine and HbAlc level of normal, diabetic and drug-treated rats

\begin{tabular}{|c|c|c|c|c|c|}
\hline Groups (n=6) & Insulin $(\mu \mathrm{U} / \mathrm{ml})$ & Glucose (mg/dl) & HbA1C & Urea (mg/dl) & Creatinine (mg/dl) \\
\hline $\mathrm{I}$ & $16.14 \pm 0.49$ & $75.83 \pm 6.33$ & $2.71 \pm 0.43$ & $15.39 \pm 1.06$ & $0.84 \pm 0.11$ \\
\hline II & $4.58 \pm 0.49^{* * * a}$ & $247.39 \pm 11.5^{* * * a}$ & $9.80 \pm 0.35^{* * * a}$ & $47.75 \pm 1.74^{* * * a}$ & $4.05 \pm 0.26^{* * * a}$ \\
\hline III & $9.66 \pm 0.77^{* * * b}$ & $136.48 \pm 12.19^{* * * b}$ & $6.28 \pm 0.57^{* * * b}$ & $28.06 \pm 1.66^{* * * b}$ & $2.17 \pm 0.18^{* * * b}$ \\
\hline IV & $11.85 \pm 0.85^{* * * b}$ & $121.29 \pm 7.82^{* * * b}$ & $6.11 \pm 0.31^{* * * b}$ & $23.06 \pm 1.77^{* * * b}$ & $1.58 \pm 0.20^{* * * b}$ \\
\hline V & $12.58 \pm 1.08^{* * * b}$ & $84.75 \pm 8.11^{* * * b}$ & $3.98 \pm 0.41^{* * * b}$ & $19.27 \pm 2.04^{* * * \mathrm{~b}}$ & $1.41 \pm 0.20^{* * * \mathrm{~b}}$ \\
\hline
\end{tabular}

Values are expressed as mean \pm SEM, $n=6$ in each group, ${ }^{* * *} p<0.05$-Comparison made between normal control, diabetic and drug treated. (a=normal control vs. diabetic control, $\mathrm{b}=$ diabetic control vs. treated, $\mathrm{HbA1C}=$ glycolyted haemoglobin)

Table 4: Effect of NNSE on the serum protein, albumin, globulin, SGOT, SGPT and ALP level of normal, diabetic induced and drug treated rats

\begin{tabular}{|c|c|c|c|c|c|c|}
\hline $\begin{array}{l}\text { Groups } \\
(n=6)\end{array}$ & Protein (g/dl) & Albumin (g/dl) & Globulin (g/dl) & $\begin{array}{l}\text { SGPT } \\
(\text { ALT) }(U / I)\end{array}$ & $\begin{array}{l}\text { SGOT } \\
(\text { AST) }(U / I)\end{array}$ & ALP (U/l) \\
\hline \multirow[t]{2}{*}{ I } & 9.54 & 4.98 & 4.11 & 15.56 & 21.64 & 170.17 \\
\hline & \pm 0.52 & \pm 0.28 & \pm 0.47 & \pm 1.36 & \pm 2.23 & \pm 8.10 \\
\hline \multirow[t]{2}{*}{ II } & 5.56 & 3.99 & 2.54 & 54.90 & 59.69 & 308.24 \\
\hline & $\pm 0.67^{* *_{a}}$ & $\pm 0.14^{* a}$ & $\pm 0.24^{* a}$ & $\pm 1.88^{* * * a}$ & $\pm 2.82^{* * * a}$ & $\pm 9.48^{* * * a}$ \\
\hline \multirow[t]{2}{*}{ III } & 8.09 & 4.52 & 2.77 & 27.60 & 32.42 & 210.67 \\
\hline & $\pm 0.80^{\mathrm{b}}$ & $\pm 0.25^{\mathrm{b}}$ & $\pm 0.36^{\mathrm{b}}$ & $\pm 1.42^{* * * b}$ & $\pm 2.31^{* * * \mathrm{~b}}$ & $\pm 8.73^{* * * b}$ \\
\hline \multirow[t]{2}{*}{ IV } & 8.88 & 4.40 & 3.42 & 23.90 & 27.25 & 201.10 \\
\hline & $\pm 0.97^{* \mathrm{~b}}$ & $\pm 0.15^{\mathrm{b}}$ & $\pm 0.35^{\mathrm{b}}$ & $\pm 1.82^{* * * \mathrm{~b}}$ & $\pm 1.54^{* * * \mathrm{~b}}$ & $\pm 6.80^{* * * \mathrm{~b}}$ \\
\hline \multirow[t]{2}{*}{ V } & 9.35 & 4.68 & 3.60 & 18.76 & 21.85 & 175.24 \\
\hline & $\pm 0.84^{* \mathrm{~b}}$ & $\pm 0.24^{*} \mathrm{~b}$ & $\pm 0.41^{\mathrm{b}}$ & $\pm 1.70^{* * * \mathrm{~b}}$ & $\pm 2.08^{* * * \mathrm{~b}}$ & $\pm 9.79^{* * * \mathrm{~b}}$ \\
\hline
\end{tabular}

Values are expressed as mean \pm SEM, $n=6$ in each group, ${ }^{* * *} p<0.05$-Comparison made between normal control, diabetic and drug-treated (a=normal control vs. diabetic control, $\mathrm{b}=$ diabetic control vs. treated, ALT= alanine transaminase, $\mathrm{AST}=$ aspartate transaminase, $\mathrm{ALP}=$ alkaline phosphatase) 


\section{Biochemical parameters}

The levels of total protein, albumin, globulin and liver marker enzymes like SGPT, SGOT and ALP in the serum of diabetic rats are estimated. The diabetic control rats (Group II) had decreased levels of serum protein, albumin, globulin and elevated levels of liver marker enzymes as compared with normal control rats (Group I). After treatment with the NNSE at 200 and $400 \mathrm{mg} / \mathrm{kg} \mathrm{b}$. w doses (Groups III, IV) and glibenclamide as a standard drug (Group V), the total protein, albumin, globulin and liver marker enzymes were brought back to near normal levels (table 4).

\section{Lipid profiles}

The treatment with NNSE (200 and $400 \mathrm{mg} / \mathrm{kg}$ ) showed significant $(p<0.05)$ reduction in cholesterol level $(132.52 \pm 1.15$ and $110.22 \pm 1.15 \mathrm{mg} / \mathrm{dl})$ as compared with the diabetic control group $(179.09 \pm 0.98 \mathrm{mg} / \mathrm{dl})$ after a few weeks of treatment.

Effect of NNSE on Total cholesterol

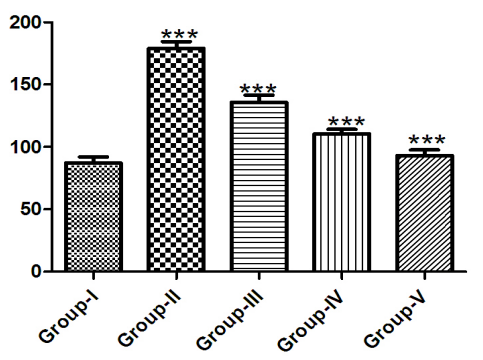

Effect of NNSE on HDL

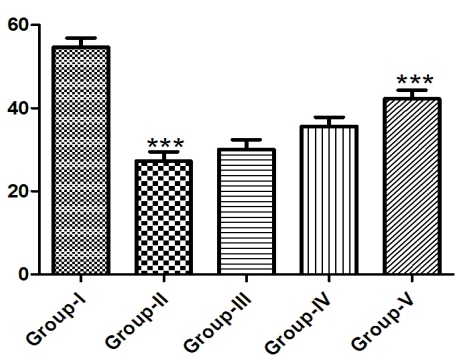

Effect of NNSE on VLDL

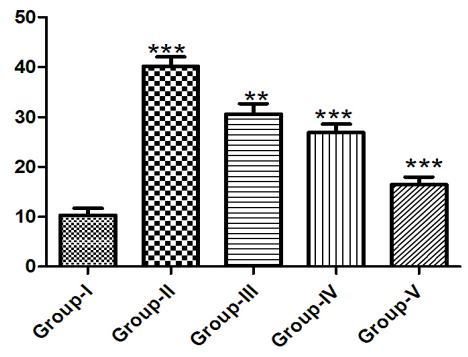

Treatment with NNSE significantly $(p<0.05)$ decreases the triglyceride level (TG) level as compared with the diabetic control group. Similarly, there was a significant reduction in the levels of low-density lipoprotein (LDL) from $(128.96 \pm 1.05$ to $82.88 \pm 0.57$ $\mathrm{mg} / \mathrm{dl}$ ) with the NNSE at $400 \mathrm{mg} / \mathrm{kg}$ body weight doses compared with the diabetic control group. Moreover, NNSE and the standard drug group showed significant reduction $(p<0.05)$ in very lowdensity lipoprotein (VLDL) level when compared with the diabetic control group. It was observed from the results that the serum levels of total cholesterol (TC), triglyceride (TG), very low-density lipoprotein (VLDL) and low-density lipoprotein (LDL) was significantly increased on the other hand serum high-density lipoprotein (HDL) level was significantly $(p<0.05)$ decreased in diabetic rats compared to a normal control group. After treatment with the NNSE at 200 and $400 \mathrm{mg} / \mathrm{kg}$ body weight doses the levels of TC, TG, VLDL, and LDL were significantly decreased, with significantly increased serum HDL level (fig. 1).

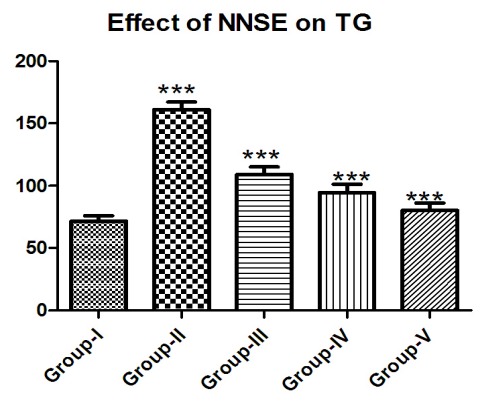

Effect of NNSE on LDL

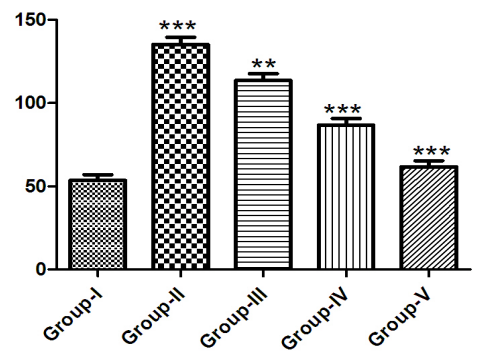

Effect of NNSE on Glycogen

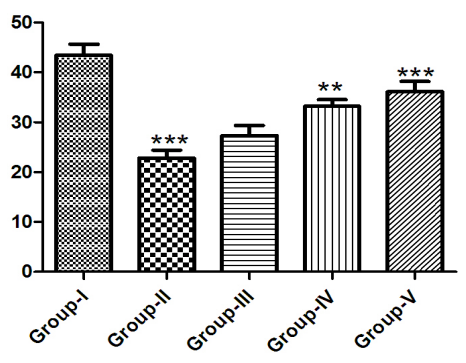

Fig. 1: Effect of NNSE on serum lipid profile and glycogen in STZ induced diabetic rats. (Values are expressed as mean \pm SEM, $n=6$ in each group, ${ }^{* * *} \mathbf{p}<0.05$-Comparison made between normal control, diabetic and drug treated. $\mathrm{TG}=$ triglyceride, $\mathrm{HDL}=\mathrm{high}$ density lipoprotein, LDL=low density lipoprotein, VLDL=very low-density lipoprotein)

\section{Effect of NNSE on antioxidant enzymes}

Various oxidative stress parameters like catalase (CAT), glutathione peroxidase (GPx), superoxide dismutase (SOD), lipid peroxidation (LPO) and reduced glutathione (GSH) levels were estimated in serum, liver and kidney. It was observed that diabetic rats were found to have decreased CAT, GPx, SOD and GSH enzyme in serum, liver and kidney as compared with control. Administration of seed extracts to the diabetic rats resulted in a significant $(p<0.05)$ increase in the levels of SOD, GSH, GPX and CAT (fig. 2-4). Diabetic rats were found to exhibit significant $(p<0.05)$ increase of lipid peroxidase in serum, liver and kidney compared to control rats. Treatment with NNSE produced significant $(p<0.05)$ decrease in LPO. It was observed that antioxidant enzyme levels were found to be decreased in the diabetic control group as compared to a normal control group.

However, antioxidant enzyme level was maintained for normal for both glibenclamide group and NNSE treated groups (200 and 400 $\mathrm{mg} / \mathrm{kg}$ ) (fig. 2-4). 

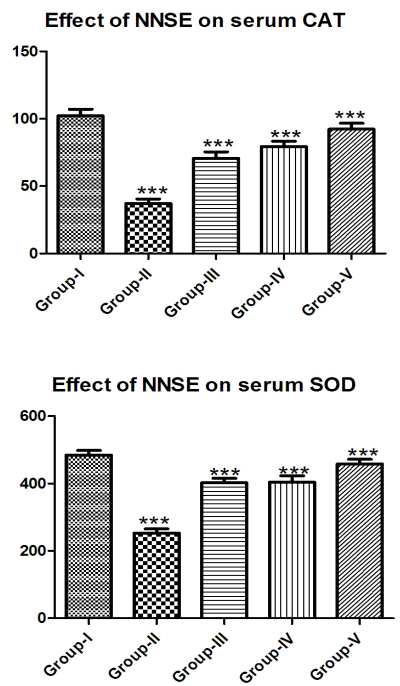

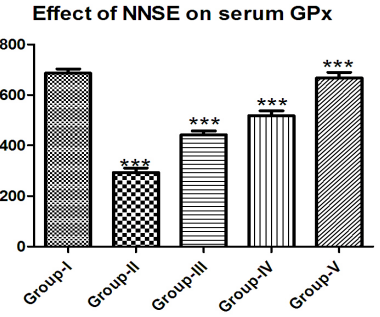

Effect of NNSE on serum LPO

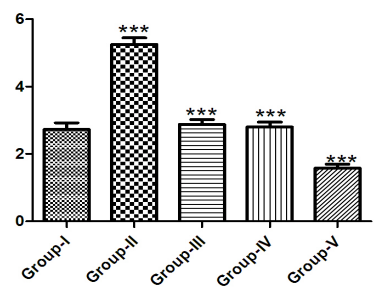

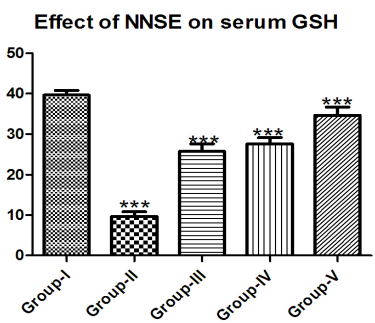

Fig. 2: Effect of NNSE on Serum CAT, GPx, SOD, LPO and GSH in the normal, diabetic and drug-treated rats [(Values are expressed as mean \pm SEM, $n=6$ in each group, ${ }^{* * *} \mathbf{p}<0.05$-Comparison made between normal control, diabetic and drug treated. Catalase (CAT), glutathione peroxidase (GPX), superoxide dismutase (SOD), lipid peroxidation (LPO) and reduced glutathione (GSH)]

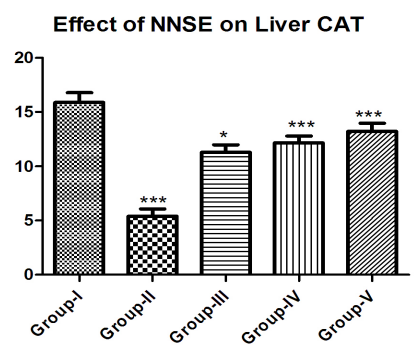

Effect of NNSE on Liver SOD

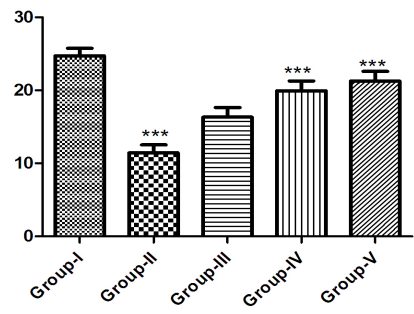

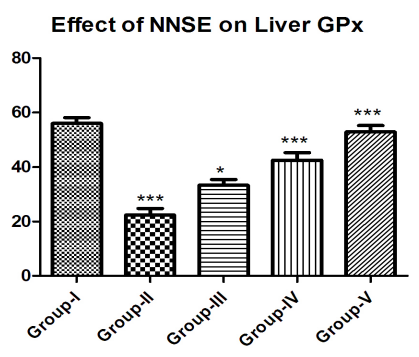

Effect of NNSE on Liver LPO
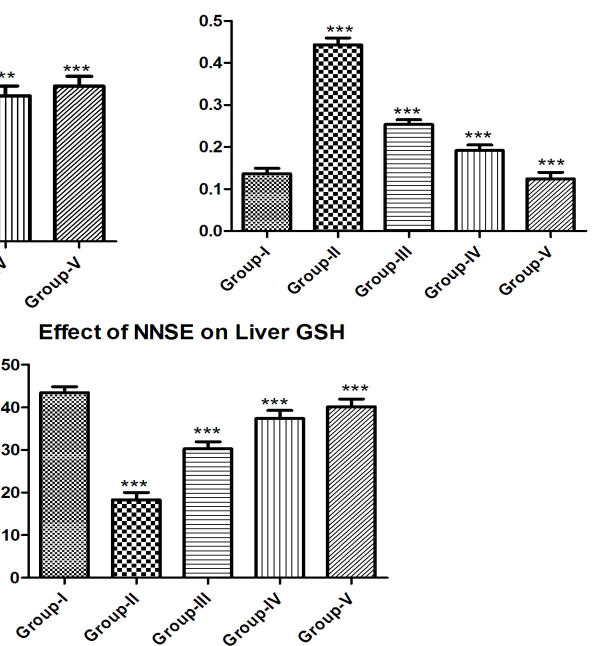

Fig. 3: Effect of NNSE on Liver CAT, GPx, SOD, LPO and GSH in the normal, diabetic and drug-treated rats. [(Values are expressed as mean $\pm S E M, n=6$ in each group, ${ }^{* * *} p<0.05$-Comparison made between normal control, diabetic and drug treated. Catalase (CAT), glutathione peroxidase (GPX), superoxide dismutase (SOD), lipid peroxidation (LPO) and reduced glutathione (GSH)] 
Effect of NNSE on Kidney CAT

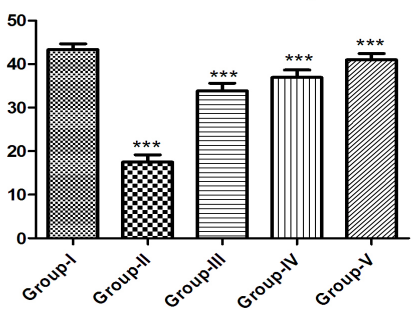

Effect of NNSE on Kidney SOD

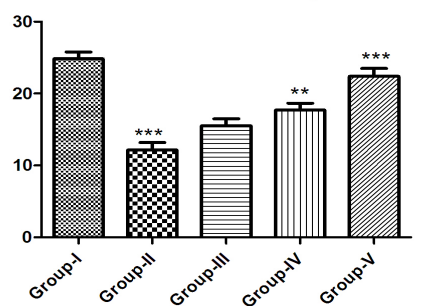

Effect of NNSE on Kidney GPx

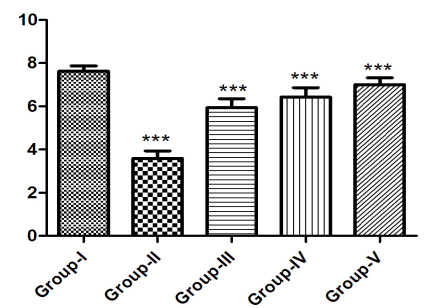

Effect of NNSE on Kidney LPO

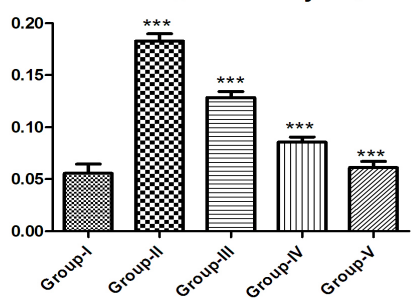

Effect of NNSE on Kidney GSH

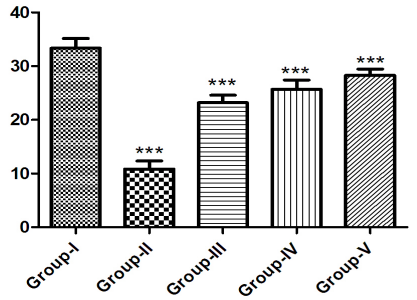

Fig. 4: Effect of NNSE on Kidney CAT, GPx, SOD, LPO and GSH in the normal, diabetic and drug-treated rats [(Values are expressed as mean $\pm S E M, n=6$ in each group, ${ }^{* * *} \mathbf{p}<0.05$-Comparison made between normal control, diabetic and drug treated. Catalase (CAT), glutathione peroxidase (GPX), superoxide dismutase (SOD), lipid peroxidation (LPO) and reduced glutathione (GSH)]

\section{DISCUSSION}

Diabetes mellitus (DM) is becoming a pandemic worldwide. The highest percentages of increases in disease prevalence are in developing nations, with a major increase in the Middle-East, SubSaharan Africa, South Asia, and Latin America. WHO listed 10 countries to have the highest numbers of people with diabetes in 2000 and 2030 [29].

Diabetes mellitus is a global epidemic with an estimated worldwide prevalence and according to 2006 3rd edition of the diabetes atlas the estimates were of 246 million people worldwide with diabetes since 2007, and an anticipated 380 million in 2025 [30].

India also has the highest number of diabetic patients, and India is being called the diabetic capital of the world [31].

The present investigation highlights the antidiabetic efficacy of NNSE. In STZ induced diabetic rats treated with the seed extract, dose-dependent reduction in blood glucose level was observed. STZ causes massive destruction of $\beta$-cells of the islets of Langerhans resulting in the reduced synthesis and release of insulin. This leads to hyperglycemia and diabetes [32].

In diabetic condition, elevated blood glucose, reduction in body weight, symptoms like polyuria, polydipsia and polyphagia are commonly observed. In the present study, it was observed that there is a reduction in body weight of the STZ induced diabetic rats which may be due to catabolism of fats and protein [33]. The administration of NNSE improve body weight compared to diabetic control rats, which indicates the preventive effect of plants on the degradation of proteins. The increase in blood glucose level after STZ administration may be due to insulin deficiency (ID) or insulin resistance (IR) in diabetic rats. It was found that NNSE significantly $(p<0.05)$ reduced blood glucose level in diabetic rats, which represents a reversal of insulin resistance or increasing insulin secretion due to the regeneration of damaged pancreatic $\beta$-cells in STZ induced diabetic rats [34].
In the present study, a significant $(p<0.05)$ increase in serum urea and creatinine levels were observed in diabetic rats compared to normal control rats, which indicate an impaired renal function in diabetic rats due to elevated glucose and glucosylated protein tissue levels. The treatment with NNSE lowered the above parameters significantly $(p<0.05)$ as compared to diabetic control rats and it showed a protective effect of ethanol extract of NNSE on the kidney [35].

In diabetes, $\mathrm{HbA} 1 \mathrm{c}$ is considered as a diagnostic marker and helps to know long-term blood sugar level and complications associated with diabetes [36, 37]. HbA1c has been found to be increased over a long period of time in diabetes. During diabetes, the excess of glucose present in the blood reacts with haemoglobin to form glycosylated haemoglobin [38]. In the present study, STZ induced diabetic rats showed a significant $(p<0.05)$ increase in HbA1c level as compared with normal rats. The ethanol extracts of NNSE showed a significant $(p<0.05)$ decrease in the content of HbA1c.

It is very clear from the results presented that there is a significant $(p<0.05)$ reduction in serum protein, albumin and globulin levels were observed in STZ induced diabetic control rats (Group-II), when compared to normal control (Group-I) and glibenclamide treated rats (Group-V). Protein, albumin, and globulin levels were found to be restored to normal by the administration of NNSE to the diabetic rats [39-40]. The increased levels of serum protein, albumin and globulin in STZ induced diabetic rats are presumed to be due to increased protein catabolism and gluconeogenesis during diabetes [41].

Elevation of serum biomarker enzymes such as SGOT, SGPT and ALP was observed in STZ induced diabetic rats, indicating impaired liver function, which is obviously due to hepatocellular necrosis. Treatment with NNSE and a standard drug (glibenclamide) resulted in a decrease of transaminase activities in STZ induced diabetic rats. In this study, it was observed that levels of ALP, SGPT and SGOT in STZ induced diabetic rats were elevated. It may be due to leaking out of enzymes from the tissues and migrating into the circulation due to the adverse effects of STZ [42]. Diabetic complications such as 
increased gluconeogenesis and ketogenesis may be due to elevated transaminase activities. SGOT and SGPT levels are indicators of liver function. Hence restoration of normal levels indicates the normal function of liver [43].

Impaired serum lipid levels are another complication, resulted in the dyslipidemic condition in diabetes [44]. Elevated TG, TC, LDL and VLDL levels are the primary factors for coronary artery disease (CAD) and atherosclerosis. It was observed that NNSE significantly $(p<0.05)$ reduced the TG, TC, LDL and VLDL and improved HDL level as compared to control. These results proved that NNSE had good antidiabetic and hypolipidemic effect on STZ induced diabetic rats.

The levels of serum lipid profiles, total cholesterol (TC), triglycerides (TG), HDL-C, LDL-C, VLDL-C, LDL/HDL ratio in control and experimental rats were investigated in the present study. When compared to normal rats, the STZ-induced diabetic rats showed a significant $(p<0.05)$ increase in serum lipid profiles except HDL-C, which was in decreased level in the diabetic rats than normal rats. The diabetic rats treated with NNSE and glibenclamide showed a significant decrease in the content of lipid profiles compared to diabetic control rats. Similarly, HDL-C level increased in NNSE treated rats when compared to diabetic rats. The impairment of insulin secretion results in the enhanced metabolism of lipids from the adipose tissue to the plasma. A variety of derangements in metabolic and regulatory mechanisms due to insulin deficiency are responsible for the observed accumulation of lipids [45]. Further, it has been reported that diabetic rats treated with insulin showed normalized lipid levels $[46,47]$. Diabetic rats treated NNSE and glibenclamide also showed normalized lipid levels. Thus, the results indicate that NNSE may also possess insulin-like action by virtue of the ability to lower the lipid levels. The present study reveals that the levels of serum lipid profiles are usually raised in diabetic rats, and such an elevation represents a risk factor for coronary heart diseases (CAD) [48]. Lowering the serum lipid level through dietary or drug therapy seems to be associated with a decrease in the risk of cardiovascular disease (CVD) [49].

The results of the present study showed increased lipid peroxidation (LPO) on serum, liver and kidney of STZ-induced diabetic rats. Some studies have confirmed that there is an increased lipid peroxidation in liver, kidney, and brain of diabetic rats [50-51]. Lipid peroxidation is a normal phenomenon involved in a peroxidative loss in unsaturated lipids, thus bringing about lipid degradation and membrane disorganization. Peroxidized lipid has been considered to play a significant role in the pathogenesis of several diseases and may be taken as a molecular mechanism of cell injury and inflammation under pathological conditions.

In the present study, an increase in the levels of LPO was found, and these levels were significantly reduced after the supplementation with the NNSE and glibenclamide. This indicates that NNSE inhibits oxidative damage due to the antiperoxidative effect of ingredients present in them. Apart from the regulation of carbohydrate metabolism, insulin also plays an important role in the lipid metabolism. Insulin is a potent inhibitor of lipolysis since it inhibits the activity of hormone-sensitive lipase in adipose tissue and suppresses the release of free fatty acids [52-57].

The levels of superoxide dismutase (SOD), catalase (CAT), glutathione peroxide (GPx) and reduced glutathione (GSH) in the serum, liver and kidney of the control and experimental rats were studied. A highly significant reduction in the activity of scavenging mitochondrial enzymes is observed in STZ induced rats. These adverse changes could be reversed to near normal with the treatment of NNSE and glibenclamide [58].

The antioxidant enzymes SOD and CAT play an important role in reducing cellular stress; SOD scavenges the superoxide radical by converting it to hydrogen peroxide and molecular oxygen [59] while CAT brings about the reduction of hydrogen peroxide and protects higher tissues from the highly reactive hydroxyl radicals [60]. In the present investigation, both these enzymes registered low levels of activity in diabetic controls indicating diabetes induces stress. Administration of NNSE to the diabetic rats improved both SOD and CAT activities, reflecting the antioxidant effect of the plant. The present study indicates the reduction in the ability of SOD, CAT, GPx and GSH in STZ induced diabetic rats (Group II). These results reveal the protective role of this plant extracts in decreasing lipid peroxidation by the normalizing antioxidant system.

\section{CONCLUSION}

The main objective of this study was to assess the antidiabetic and antihyperlipidemic effect of NNSE in STZ induced diabetic rats. The present study revealed that Nelumbo nucifera seed extract (NNSE) had an antihyperglycemic, hypolipidemic and antioxidant effect. The active phytoconstituents responsible for the activities are not precisely known, but it may be one or more of the active phytoconstituents established to be present in the NNSE.

\section{ACKNOWLEDGEMENT}

The first author Alok Bhardwaj is thankful to the Dr. K. P. Modi (Associate Professor) at B. K. Mody Govt. Pharmacy College, Rajkot, India, for providing general support and encouraging my work. We also thank taxonomists for identifying the plant species used in the study.

\section{CONFLICT OF INTERESTS}

\section{Declared none}

\section{REFERENCES}

1. Kumar S, Kumar V, Prakash O. Antidiabetic and hypolipidemic activities of Dillenia indica extract in diabetic rats. Zhongxiyi Jiehe Xuebao 2011;9:570-4.

2. Ananda PK, Kumarappan CT, Christudas S, Kalaichelvan VK. Effect of Biophytum sensitivum on streptozotocin and nicotinamide induced diabetic rats. Asian Pac J Trop Biomed 2012;2:31-5.

3. Bandawane D, Juvekar A, Juvekar M. The antidiabetic and antihyperlipidemic effect of Alstonia scholaris linn bark in streptozotocin Induced diabetic rats. Indian J Pharm Educ Res 2011;45:114-20.

4. Kumar S, Malhotra R, Kumar D. Antidiabetic and free radical scavenging potential of Euphorbia hirta flower extract. Indian J Pharm Sci 2010;72:531-3.

5. Ramachandran V, Mandal D, Payyavala U, Sangai PD, Muthureddy NS, Shanish A, et al. Hypoglycemic, antioxidant and hypolipidemic activity of Asparagus racemosus on streptozotocin-induced diabetic rats. Adv Appl Sci Res 2011;2:179-85.

6. Kumar S, Rashmi Kumar D. Evaluation of the antidiabetic activity of Euphorbia hirta Linn. in streptozotocin-induced diabetic mice. Indian J Nat Prod Resour 2010;1:200-3.

7. Shen MJ, Schopf JW, Harbottle G, Cao RJ, Ouyang S, Zhou KS, et al. Long-living lotus: germination and soil irradiation of centuries-old fruits, and cultivation, growth, and phenotypic abnormalities of offspring. Am J Bot 2002;89:236-47.

8. Jangra M, Sharma S, Kumar M. Evaluation of antihyperglycemic activity of Dodonaea viscosa leaves in normal and STZ diabetic rats. Int J Pharm Pharm Sci 2011;3:69-74.

9. Manimekalai P, Krishnaraju V, Davidraj C, Ssudhakar B, Dhanalakshmi R, Kalpana K. The effect of a hydroalcoholic extract of Nelumbo nucifera $(G)$ on STZ induced diabetic rats. Int J Pharm World Res 2010;1:1-16.

10. Vessal M, Hemmati M, Vasei M. Antidiabetic effects of quercetin in streptozotocin-induced diabetic rats. Comp Biochem Physiol 2003;3:357-64.

11. Anderson L, Dinesen B, Jorgonsen PN, Poulsen F, Roder MF. Enzyme immune assay for intact human insulin in serum or plasma. Clin Chem 1993;38:578-82.

12. Trinder P. Determination of glucose in blood using glucose oxidase with an alternative oxygen acceptor. Ann Clin Biochem 1969;6:24.

13. Sudhakar NS, Pattabiraman TN. A new colourimetric method for the estimation of glycosylated hemoglobin. Clin Chin Acta 1981;109:267-74.

14. Varley H. Practical clinical biochemistry, Arnold Heinemann Publication Pvt. Ltd; 1976. p. 452.

15. Owen JA, Iggo JB, Scangrett FJ, Steward IP. Determination of creatinine in plasma, serum, a critical examination. J Biochem 1954;58:426-37. 
16. Lowry $\mathrm{OH}$, Rosenbrough NJ, Farr AL, Randall RJ. Protein measurement with the folin's phenol reagent. J Biol Chem 1951;193:265-75.

17. Reitman S, Frankel S. A colourimetric method for the determination of serum glutamic oxalacetic and glutamic pyruvic transaminases. Am J Clin Pathol 1957;28:56-63.

18. King EJ, Armstrong AR. Determination of serum and bile phosphatase activity. Can Med Assoc J 1934;31:56-63.

19. Parekh AC, Jung. Cholesterol determination with ferric acetate, uranium acetate and sulphuric acid, ferrous sulphate reagent. Anal Chem 1970;112:1423-7.

20. Rice EW. Triglycerides in serum. In: Standard Methods in Clinical Chemistry, (Ed) Roderick MP, Academic Press: New York; 1970. p. 215-22.

21. Warnick GR, Nguyan T, Albers AA. Comparison of improved precipitation methods for quantification of high-density lipoprotein cholesterol. Clin Chem 1985;31:217-22.

22. Friedewald WT, Levy RI, Fredrickson DS. Estimation of the concentration of low-density lipoprotein cholesterol in plasma, without use of the preparative ultracentrifuge. Clin Chem 1972;18:499-502.

23. Murat JC, Serfaty A. Simple enzymatic determination of polysaccharide (Glycogen) content of the animal tissue. Clin Chem 1974;20:1576-7.

24. Sinha AK. Colourimetric assay of catalase. Anal Biochem 1972; 47:389-94.

25. Rotruck JT, Pope AL, Ganther HE, Swanson AB, Hafeman DG, Hoekstra WG, Science 1973;179:588-90.

26. Kakkar P, Das B, Viswanathan PN. Indian J Biochem Biophys 1984;2:130-2.

27. Uchiyama $M$, Mihara $M$. Determination of malonaldehyde precursor in the tissues of thiobarbituric acid test. Anal Biochem 1978;86:271-8.

28. Ellaman GL. Tissue sulfhydryl group. Arch Biochem Biophys 1995;82:70-7.

29. Wild S, Roglic G, Green A. Global prevalence of diabetes: estimates for the year 2000 and projections for 2030. Diabetes Care 2004;27:1047-53.

30. Wild S, Roglic G, Green A, Sicree R, King H. Global prevalence of diabetes, estimates for the year 2000 and projections for 2030 . Diabetes Care 2004;27:1047-53.

31. Kumar A, Goel MK, Jain RB, Khanna P, Chaudhary V. India towards diabetes control: key issues. Australasian Med J 2013;6:524-31.

32. Szkudelski T. The mechanism of alloxan and streptozotocin action in B cells of the rat pancreas. Physiol Res 2001;50:536-46.

33. Veeramani C, Pushpavalli G, Pugalendi KV. Antihyperglycaemic effect of Cardiospermum halicacabum Linn. leaf extract on streptozotocin-induced diabetic rats. J Appl Biomed 2008;6:19-26.

34. Sezik E, Aslan M, Yesilada E, Ito S. Hypoglycaemic activity of Gentiana olivieri and isolation of the active constituent through bioassay-directed fractionation techniques. Life Sci 2005;76:1223-8.

35. Lal SS, Sukla Y, Singh A, Andriyas EA, Lall AM. Hyperuricemia, high serum urea and hypoproteinemia are the risk factor for diabetes. Asian J Med Sci 2009;1:33-4.

36. Deguchi Y, Miyazaki K. Anti-hyperglycemic and antihyperlipidemic effects of guava leaf extract. Nutr Metab 2010;7:9.

37. Alagammal M, Nishanthini A, Mohan VR. Antihyperglycemic and antihyperlipidemic effect of Polygala rosmarinifolia wright and arn on alloxan induced diabetic rats. J Appl Pharm Sci 2012;2:143-8.

38. Lanjhiyana S, Garabadu D, Ahirwar D, Bigoniya P, Rana AC, Patra KC, et al. Antidiabetic activity of methanolic extract of stem bark of Elaeodendron glaucum pers. in an alloxanized rat model. Adv Appl Sci Res 2011;2:47-62.

39. Kala SMJ, Tresina PS, Mohan VR. The antioxidant, antihyperlipidaemic and antidiabetic activity of Eugenia singampattiana Bedd. leaves in alloxan-induced diabetic rats. Int J Pharm Pharm Sci 2012;4:412-6.
40. Alagammal M, Paulpriya K, Mohan VR. Evaluation of antiinflammatory activity of ethanol extract of Polygala javana DC. whole plant. Int Res J Pharm 2012;3:212-3.

41. Palanivel $\mathrm{R}$, Thangavel $\mathrm{M}$, Selvendran K, Sakthisekaran D. Insulinomimetric effect of ammonium paratungstate on protein metabolism in streptozotocin-induced diabetic rats. Biomedical 2001;21:23-30.

42. Stanley P, Prince M, Menon VP. Hypoglycemic and other related actions of Tinospora cordifolia roots in alloxan-induced diabetic rats. J Ethnopharmacol 1999;70:9-15.

43. Ghosh S, Suryawanshi SA. Effect of Vinca rosea extract in the treatment of alloxan diabetes in male albino rats. Indian J Exp Biol 2001;39:748-59.

44. Mooradian AD. Dyslipidemia in type 2 diabetes mellitus. Nat Clin Pract Endocrinol Metab 2009;5:150-9.

45. Rajalingam R, Srinivasan N, Govindarajulu P. Effect of alloxan induced diabetes on lipid profiles in renal cortex and medulla of mature albino rats. Indian J Exp Biol 1993;31:577-9.

46. Pathak RM, Ansai S, Mahmood A. Changes in the chemical composition of intertional brush border membrane in alloxan induced chronic diabetes. Indian J Exp Biol 1981;19:503-5.

47. Maruthupandian A, Mohan VR, Sampathraj. The antidiabetic, anti-hyperlipidemic and antioxidant activity of Wattakaka volubilis (L. F) Stapf. leaves in alloxan-induced diabetic rats. Int J Pharm Sci Res 2010;1:83-90.

48. Mironova MA, Klein RL, Virella GL, Lopes-Virella MF. Antimodified LDL antibodies, LDL-containing immune complexes and susceptibility of LDL to in vitro oxidation in patients with type-2 diabetes. Diabetes 2000;49:1033-49.

49. Scott M, Grundy. Diabetis cardiovas. Dis Circ 1999;100:113446.

50. Flowers on brain lipid peroxidation in rats treated with streptozotocin. Mol Cell Biochem 2003;243:23-8.

51. Ananthan R, Latha M, Ramkumar KM, Pari L, Basker L, Narmatha BV. The Antidiabetic effect of Gymnema montanum leaves Effect on lipid peroxidation induced oxidative stress in experimental diabetes. Nutrition 2004;6:379-86.

52. Pari L, Latha M. Effect of Cassia auriculata flowers on blood sugar levels, serum and tissue lipids in streptozotocin diabetic rats. Singapore Med J 2002;43:617-21.

53. Prince PSM, Menon VP. Effect of Syzigium cumini in plasma antioxidants on alloxan-induced diabetes in rats. J Clin Biochem Nutr 1998;25:81-6.

54. Prince PSM, Kamalakkannan N, Menon VP. Antidiabetic and antihyperlipidaemic effect of alcoholic syzigium cumini seeds in alloxan induced diabetic albino rats. J Ethnopharmacol 2004; $91: 209-13$.

55. Prince PSM, Menon VP, Gunasekaran G. Hypolipidaemic action of Tinospora cordifolia root extract in alloxan diabetic rats. J Ethnophamacol 1999;14:4-16.

56. Latha M, Pari L. Modulatory effect of Scoparia dulcis in oxidative stress-induced lipid peroxidation in streptozotocin diabetic rats. J Med Food 2003;6:379-86.

57. Loci AS, Shaabha M, Khazraji AL, Hussain A, Twaija A. Hypoglycemic effect of a valuable extract of Artemisia herbaalba II. Effect of a valuable extract on some blood parameters in diabetic animals. J Ethnopharmacol 1994;43:167-71.

58. Nishanthini A, Mohan VR. Antioxidant activity of Polygala rosmarinifolia Wight and Arn. The whole plant in alloxan induced diabetic rats. Int Res J Pharm 2012;3:223-5.

59. Robinson $\mathrm{BH}$. The role of manganese superoxide dismutase in health and disease. J Inherited Metab Dis 1998;21:598-603.

60. Brioukhanov AL, Netrusov AI. Catalase and superoxide dismutase: distribution, properties, and physiological role in cells of strict anaerobes. Biochem 2004;69:949-62.

\section{How to cite this article}

- Alok Bhardwaj, Ketan P Modi. The antidiabetic and antihyperlipidemic activity of Nelumbo nucifera gaertn ethanol seed extract in streptozotocin-induced diabetic rats. Int J Pharm Pharm Sci 2017;9(10):197-204. 